\title{
BACTERIAL ANEURYSM
}

\author{
BY
}

\section{E. NOBLE CHAMBERLAIN}

From the Heart Departments, Royal Infirmary and Smithdown Road Hospital, Liverpool.

Received January 22, 1943

Stengel and Wolferth (1923) made an extensive review of the literature of mycotic or bacterial aneurysms. Since that time a number of cases have been recorded presenting unusual clinical or pathological features. Three new cases are described in the present paper, and, at the same time, nineteen cases reported since 1923 have been analysed.

\section{PATHOLOGY}

Most of the earlier theories as to the causation of bacterial aneurysms-a term that is preferable to mycotic which suggests a fungoid infection-laid emphasis on the mechanical production of this condition. Ponfick (1873) thought that the aneurysm was due to an embolus containing a spine of calcareous deposit which secured penetration of the vessel wall and allowed the entry of bacteria: no further evidence has been adduced to support this view. It was also suggested that, whilst embolism was the commonest cause, the aneurysm was produced by the mechanical effects of the embolus at the site of obstruction. Goodhart (1877) first advanced the hypothesis that infective processes were concerned. Since Eppinger's work (1887), it has been generally conceded that the aneurysm forms as a result of the bacterial infection of the vessel wall carried by the embolus, and is therefore more likely to occur in bacterial endocarditis and other septic conditions in which the emboli are heavily charged with bacteria. Emboli from infected valves tend to lodge, as Eppinger pointed out, at mechanical turns or sudden narrowings of the vessels. In smaller vessels it is reasonable to suppose, and has been demonstrated, that the embolus may be sufficiently large to block the vessel directly. Aneurysms in such cases are not very common because the blood ceases to pound against the damaged vascular wall. When a large vessel is affected, as in Case I of this paper, it is probable that the embolus lodges in the vasa vasorum, causing an area of infection and weakening at this point; the vessel is not obstructed and the arterial pressure rapidly produces an aneurysm in the weakened area. Usually it is not possible to identify the embolus or even the affected area post-mortem, owing to the rapid changes taking place in the vessel wall and the tendency to perforation with the formation of a false aneurysm, but there are well-established cases in which the embolus has been recognized. Eppinger found the same organisms present in the wall of the aneurysm and in the vegetations on the heart valves. In a more recent case, Lippincott (1940) identified cocci in the vasa vasorum in a case of aortic bacterial aneurysm. More rarely a bacterial aneurysm develops as a result of direct spread, along the intima of the vessel wall, of infection from neighbouring foci. A good example of this is seen in the development of aortic aneurysms arising from contiguous aortic valve lesions. Still less frequently aneurysms result from periarteritis, the arterial wall becoming infected from some external focus. Probably some such state of affairs prevails in the vessels in areas of tuberculous lung infiltration and is eventually responsible for the hæmorrhage.

In the present analysis of 22 cases, 13 showed positive signs of bacterial endocarditis. $\mathrm{K}$ 
The origin of the others was varied. Lippincott's case was associated with pneumonia, septicæmia, and septic arthritis. Aschner (1932) recorded one in which an aneurysm of the aorta resulted from an infective arteritis of uncertain origin; this was thought to be due to " metastatic ulcerous aortitis" and a gonococcus was isolated from a blood cuiture. In two cases the aneurysm was associated with a septicæmia of uncertain origin, and in another (Crane, 1937) sepsis of the foot appeared to be the focus of infection. In two cases trauma seems to have played a part. In one, recorded by Bain and Wray (1941), there was a suggestion of trauma resulting in rupture of the aortic valve, and this was followed by bacterial endocarditis causing an aneurysm from the base of the ruptured valve: the case might well be used as an example of aneurysm from spread of contiguous infection. In the second case (Taylor and Reinhardt, 1939) both sepsis and trauma were concerned; the aneurysm was in the right common iliac artery and developed as a result of pyonephrosis in association with the trauma of ureteric catheterisation.

Size.-The size of the aneurysm was often unrecorded, but when details were available the tumour rarely reached any considerable size unless by perforation it formed a false aneurysm. Such was the case in the writer's example of aneurysm of the femoral artery which attained proportions of 3-4 in. in length and 1.5 in. in diameter. Most bacterial aneurysms are not more than a few cubic centimetres in capacity. A remarkable exception was recorded by Mims Gage, an aneurysm of the common iliac artery reaching the size of a grape-fruit and being ligated during a period of bacteriological recovery.

Bacteriology.-Where a causal organism has been identified it was usually a streptococcus, as would be expected from the frequent association of bacterial aneurysms with infective endocarditis. Amengst rarer organisms, gonococci and typhoid and anthrax bacilli have been mentioned. In recording his gonococcal case, Aschner mentions that seven others had previously been described. A case of particular interest is that of Knighton (1937-8) in which the identified organism was Bacillus abortus causing a septicæmia with doubtful bacterial endocarditis.

Vessels Affected.-The site of bacterial aneurysm was stated by Stengel and Wolferth to be (in order of frequency) the aorta, abdominal arteries (superior mesenteric, splenic, and hepatic), and the cerebral and limb vessels. Mims Gage (1934) puts them in the following order: aorta, cerebral vessels, superior mesenteric arteries, and peripheral arteries, stating that the larger branches of the aorta are seldom involved. In the smaller series dealt with here, the aorta was again the most frequently affected. In 22 cases 8 involved the aorta, 3 the pulmonary artery, 2 the radial, 2 the common iliac, 2 the middle cerebral, 3 the mesenteric, 1 the popliteal, 1 the posterior tibial, 1 the femoral, 1 the axillary, and 1 the mitral valve. Often aneurysms occurred in more than one vessel, though this does not appear to be so frequent as is suggested by Eppinger. Prior to 1923, the number of cases of bacterial aneurysm of the pulmonary artery was comparatively small (in Stengel and Wolferth's series 14 out of 217 cases) and it is of interest to note that in this small series there is a relatively high incidence.

Associated Lesions. - The majority of aneurysms previously recorded seem to have been associated with common valvular lesions due to bacterial endocarditis. Amongst the 22 cases analysed here there was rather a high incidence of congenital defects, namely, 5 cases, including 1 of cor triloculare, 2 of coarctation of the aorta, and 1 of hypoplasia of the aorta. Two cases (one with coarctation) were suffering from patent ductus arteriosus. Probably these cases give a false impression of the frequency of congenital lesions as they were no doubt published partly on account of their rarity.

\section{Clinical Manifestations}

Age and Sex.-In the present series the average age was only a trifle higher than previously recorded, namely 33. Mims Gage (1934) states that most cases occur before the age of 30, 
whilst Stengel and Wolferth showed the second, third, and fourth decades to be the commonest, as contrasted with the fifth decade, the commonest for syphilitic aneurysms. Males preponderated over females, as in the series analysed by Stengel and Wolferth.

Incidence.-Bacterial aneurysms are uncommon, though if detailed autopsies were possible in all cases of bacterial endocarditis, no doubt more would be found. Garland (1932) in 12,000 autopsies found 2.2 per cent of aneurysms, of which only 4 were bacterial in origin. In the examination of some recent records of bacterial endocarditis from the files of the Royal Infirmary and Smithdown Road Hospital, Liverpool, no case of bacterial aneurysm was found except those reported here.

Course.-Some attempt has been made to determine how long the aneurysms take to develop and the duration of life thereafter. This was not easy owing to the insidious and variable course of bacterial endocarditis. In most cases it would appear that the septicæmia was present for a few months before the aneurysm was detected, but that the aneurysm itself only took a few weeks (up to two months) to attain a recognizable size. Sometimes it was possible to date the beginnings of the aneurysm by a clear history of embolism. Once present, the course of the aneurysm was usually very rapid and death generally took place within six months. Not only do bacterial aneurysms seem to occur in the more severe cases of bacterial endocarditis, but in themselves constitute a complication of great gravity owing to the risk of rupture with hæmorrhage and of vascular obstruction in the case of limb vessels. Occasionally recovery takes place. In this series three cases are recorded in which the patient was still living at the time of publication. The case of Mims Gage has already been mentioned. Nicholson (1940) described a case of coarctation of the aorta in a child of 12 with arrested subacute bacterial endocarditis and a calcified bacterial aneurysm at the seat of stricture; treatment had only been symptomatic. In another case (Knighton 1937-38) there was a clear history of embolic obstruction in the right axillary artery occurring during the course of an abortus infection in which there was also aortic regurgitation and mitral disease; after the septicæmic symptoms subsided the aneurysm continued to enlarge but was dealt with by ligation. The heart lesions, of course, persisted, leaving the prognosis uncertain.

Diagnosis.-The diagnosis of bacterial aneurysms is often impossible especially in the case of deep-seated arteries. Aneurysms of the superficial arteries, open as they are to inspection and palpation, are more easily recognized and many more might be observed if careful observation of these vessels were made during the course of bacterial endocarditis. In the present series, 6 out of 7 peripheral aneurysms were recognized clinically. In the seventh an aneurysm of the radial artery was incised as an abscess (Areta, 1935). Of the aortic aneurysms only one was recognized, that recorded by Nicholson (1940) and already described; the diagnosis depended upon radiological identification of the calcified sac. In one of the original cases described by Stengel and Wolferth, the clinical diagnosis of a bacterial aneurysm of the aorta was made by the great pulsation in the upper chest and an increase in vascular dullness in a case of bacterial endocarditis. The possibility of embolic aneurysm of the cerebral vessels has sometimes been considered when localizing signs have pointed to a sudden vascular lesion of the brain during the course of bacterial endocarditis but confirmation is impossible. Such aneurysms frequently rupture so that to the embolic features there may be added symptoms due to cerebral hæmorrhage. This is illustrated by the case of Koch and Nuzun (1940) in which an aneurysm of the right middle cerebral artery resulted from embolism during a subacute bacterial endocarditis. Subarachnoid hæmorrhage or cerebral abscess was suspected from the physical signs and the presence of blood in the cerebro-spinal fluid supported the former diagnosis.

Embolism into the mesenteric vessels is notoriously difficult of diagnosis, usually suggesting some acute abdominal catastrophe, but the possibility should not be overlooked in view of the practical importance in saving the patient an unnecessary operation. In one of 
the new cases recorded here the diagnosis was suspected whilst the patient was in hospital with bacterial endocarditis.

Treatment.-The treatment of bacterial endocarditis is most unsatisfactory even since the introduction of sulphonamide and allied therapy. It follows that bacterial aneurysms, commonly associated with bacterial endocarditis, are even less susceptible to treatment. In spite of this, out of 22 cases reviewed here, ligation of the aneurysms was possible in 2, in which the bacterial endocarditis was healed or apparently quiescent. It may be, therefore, that the development of sulphonamide therapy will lead to more cures of bacterial endocarditis and thus arrest the formation of aneurysms or permit of their surgical treatment if they develop. A great difficulty will always be the rapid development of the aneurysm to the point of rupture.

\section{Notes OF THReE CASES}

\section{Case 1.-Femoral Aneurysm.}

Admitted 1/9/1941 with history of pulsating swelling in left groin noticed the day before, preceded by soreness for one week. Rheumatic fever when aged 13 with occasional tonsillitis. Father said to have died from bursting of an aneurysm, ? aortic.

Condition on admission. Aged 35. General condition poor. Remittent pyrexia. Numerous petechiæ. No splenic enlargement. Heart: well marked aortic regurgitation. Urine: some red blood corpuscles and leucocytes. Sedimentation rate: rapid fall. Blood count: R.B.C., 3,200,000;

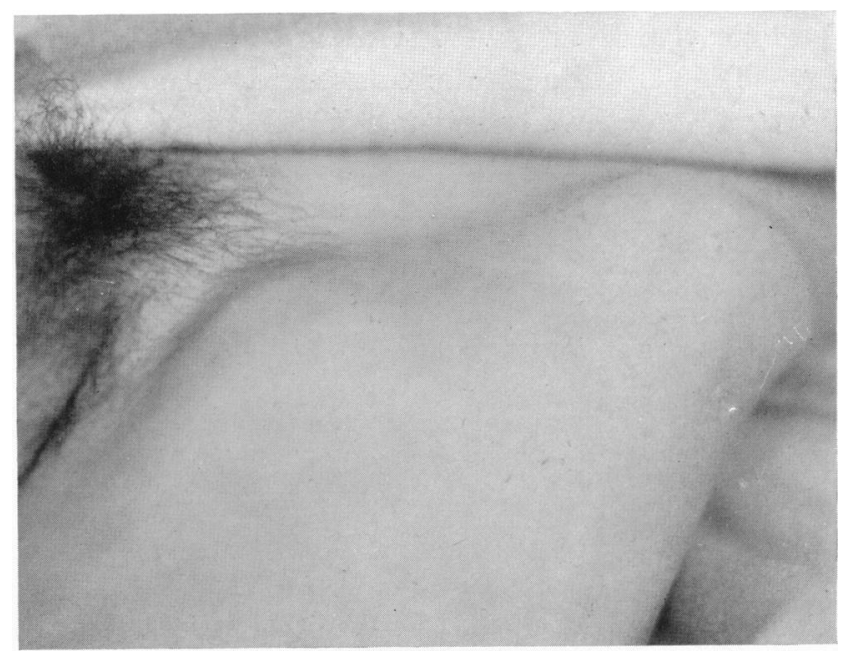

FIG. 1.-Case 1. Photograph, taken during life, showing the femoral aneurysm.

W.B.C., 9,000; Hb., 50 per cent. Gonococcal complement fixation test, positive. W.R., negative. Blood cultures, sterile. A diagnosis of bacterial endocarditis with bacterial aneurysm of the femoral artery was made.

On 19/9/1941, patient mentally confused, emaciated, and pale. Extensive purpura mainly of the trunk but including eyelid conjunctiva. Rough aortic systolic murmur with thrill, in addition to diastolic murmur of regurgitation previously found. Aneurysm larger. Loud rasping systolic murmur with thrill over the sac. Systolic and diastolic murmurs just above sac in the groin.

The patient died on $27 / 9 / 1941$.

\section{Post-mortem report. (Dr. C. V. Harrison.)}

An emaciated man, rather pale, with innumerable petechial hæmorrhages about $3 \mathrm{~mm}$. diam. scattered over body, especially over trunk. In the upper part of Scarpa's triangle on the left there is an ovoid swelling about $5 \times 7 \mathrm{~cm}$. (Fig. 1). Rigor mortis incomplete.

Cardiovascular System. Pericardium contained an excess of clear fluid. Heart slightly hypertrophied, $13 \frac{1}{2} \mathrm{oz}$. $(364 \mathrm{~g}$.). Tricuspid and pulmonary valves normal. Mitral valve, old rheumatic fibrosis and slightly stenosed (admits one finger). Infective endocarditis in the form of relatively flat warty vegetations, which have begun to spread on to the posterior auricular wall. Aortic valve also old rheumatic fibrosis and infective endocarditis similar to mitral; vegetations have spread 


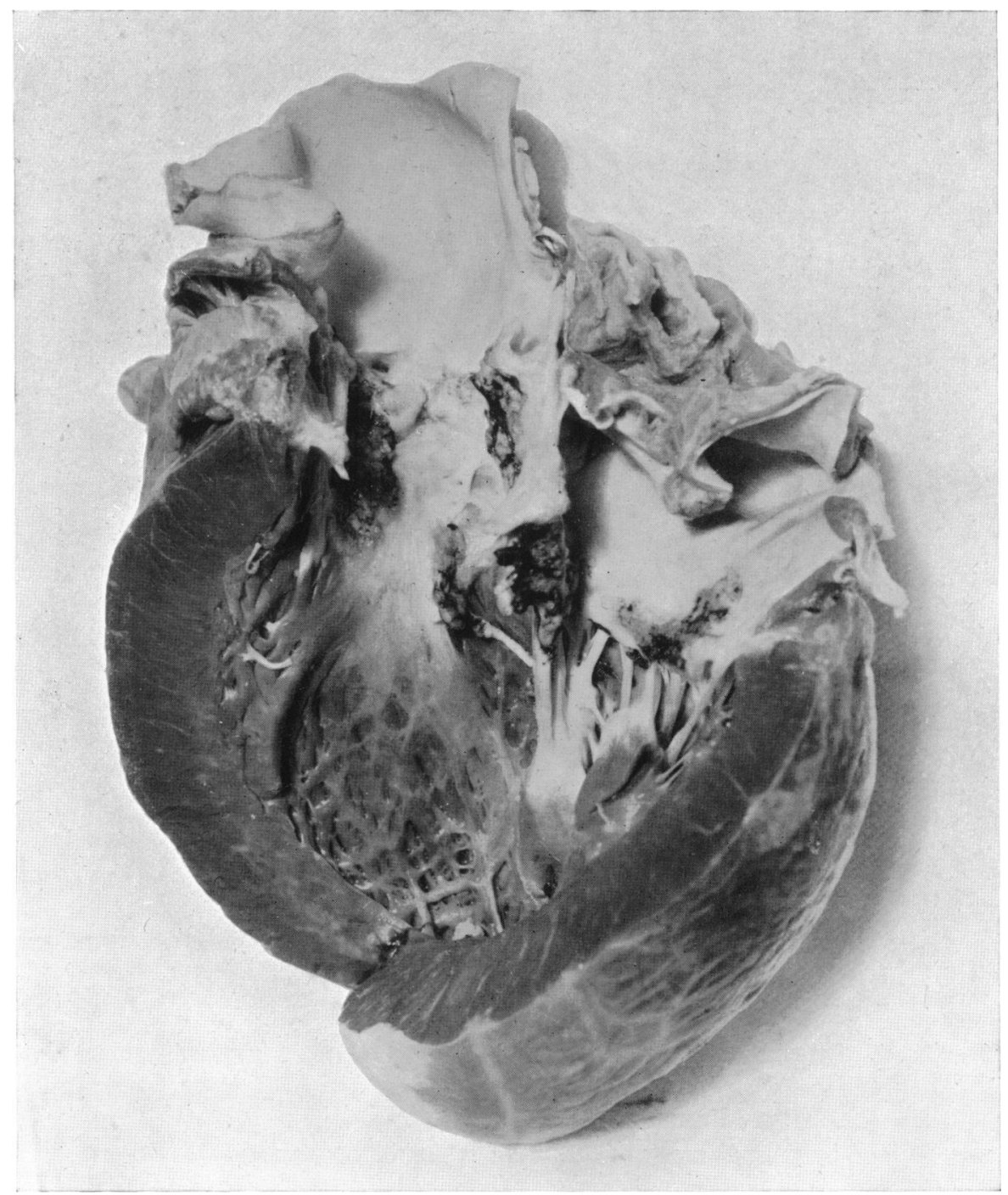

FiG. 2.-Case 1. The heart, showing vegetations on the aortic and mitral valves, due to acute bacterial endocarditis.

down on to the upper part of the interventricular septum and also on to the aortic aspect of the aortic cusp of the mitral valve. Myocardium of left ventricle, minute points of fibrosis up to $1 \mathrm{~mm}$. diameter. Coronary arteries normal. Aorta, early atheroma.

Respiratory System. Each pleura contains about 200 c.c. of clear fluid. Both lungs show œdema and there is a little early broncho-pneumonia in the upper part of the lower lobe of the left lung.

Spleen. About normal size. About two-thirds of it substance infarcted, the infarcts being large and starting to break down in the centres (Fig. 3).

Kidneys. Both show a number of infarcts. Some small and fibrosing, others larger (up to $1.5 \mathrm{~cm}$.) and recent. The right shows splotchy congestion, the left does not.

Ureters, bladder, etc., normal.

Alimentary tract and pancreas, normal. Liver, some acute congestion.

In the left groin there is an aneurysm of the left femoral artery arising just below Poupart's ligament. This is about $5 \times 5 \times 7 \mathrm{~cm}$. The anterior crural nerve is splayed out over it (Fig. 4). Apparently the aneurysm has either burst or leaked posteriorly because blood is ploughing up the muscles.

The specimen was dissected out en bloc and left to fix before opening.

Summary of Lesions. (1) Infective endocarditis superimposed on old rheumatic fibrosis of aortic and mitral valves. (2) Mycotic aneurysm of left femoral artery. (3) Infarcts of spleen and kidneys. Further dissection of the aneurysm after fixation showed that it had burst and that the wall of the 


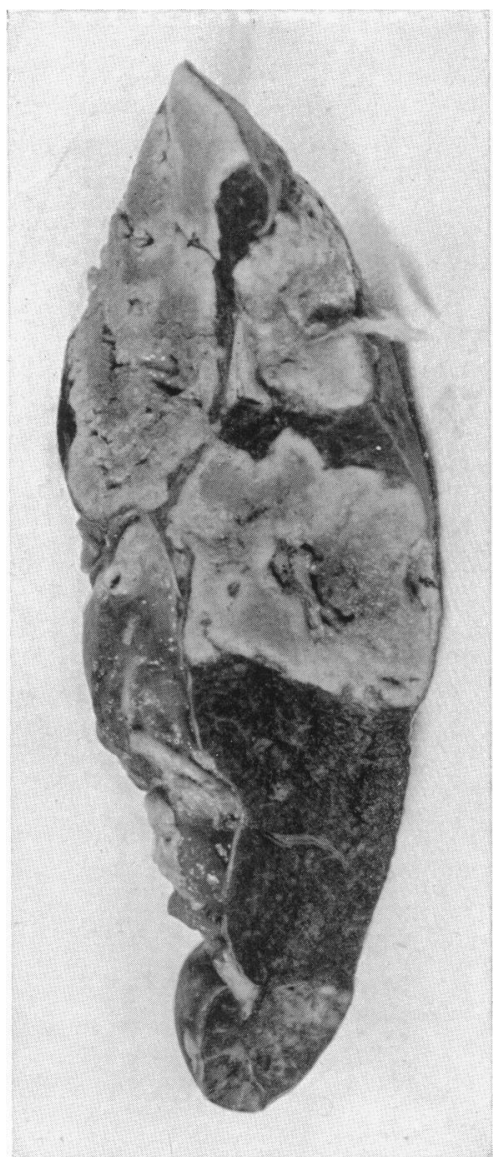

FIG. 3.-Case 1. Spleen showing numerous infarcts.

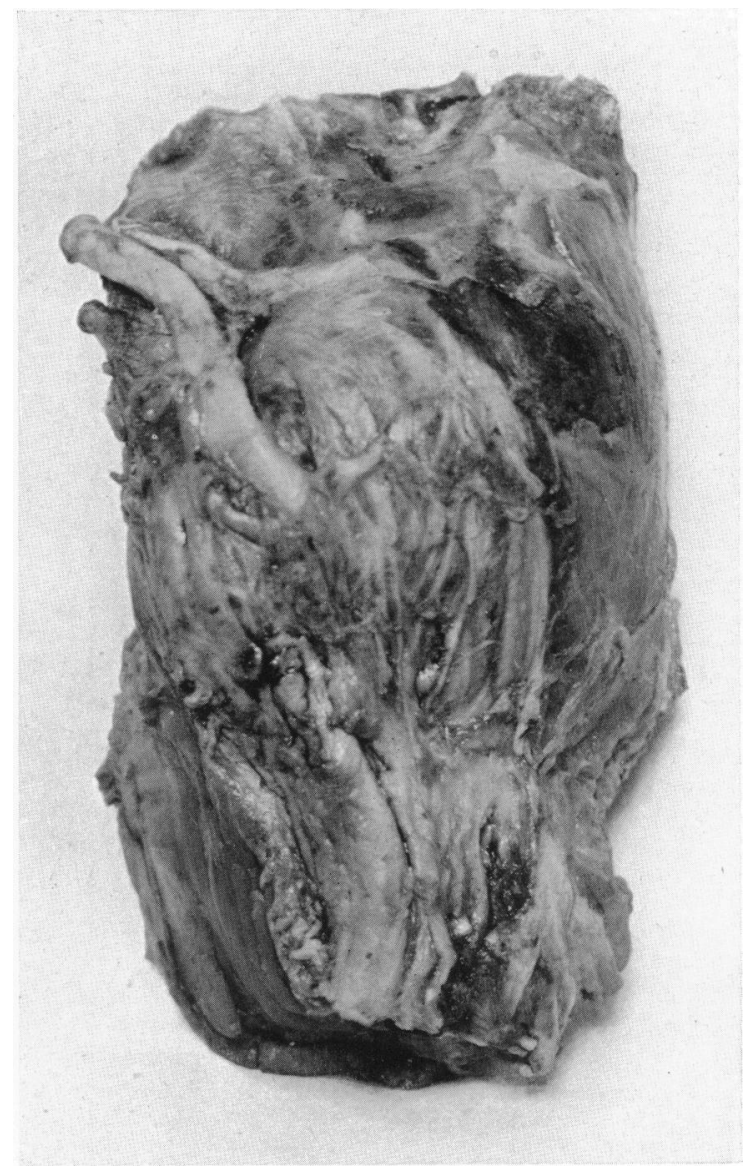

FIG. 4.-Photograph of aneurysm after dissection. Shows anterior crural nerve splayed over the mass which is chiefly due to a "false" aneurysm from leaking of original sac.

sac was now formed by the adjacent muscles. No remnants of the artery wall being visible in the parts examined.

\section{Case 2. Radial Aneurysm. (Dr. Norman Capon's case.)}

Man, aged 42. Symptoms for about three months. Anorexia, sweating, pain in the joints, fever for probably about two months.

On $7 / 9 / 1934$ very severe pain in left forearm, with nothing to show for it.

On 13/9/1934 admitted to hospital. Mitral presystolic murmur. Petechial hæmorrhages. Negative blood culture. No splenic enlargement.

On 19/10/1934. Small aneurysm on front of left forearm. Blood culture repeated-negative. Patient left hospital at own request.

On 29/1/1935 the patient died at home. Dr. Rowlands reports that he became progressively weaker and finally had convulsions, ? due to intracranial embolus.

\section{Case 3. Mesenteric Aneurysm.}

Present History. A male, aged 23, working long hours as a clerk, was admitted on 11/12/1942. Rheumatic fever, when 7 (many weeks in bed), when 14, and again when 15 . One attack since.

Tired and run down for past two months. Fleeting rheumatic pains a month ago. Red painful patches on the finger pads lasting a few days. Dr. Edwards noted fever a month ago and has kept him in bed since. Drenching night sweats, increasing pallor.

Severe abdominal pains since this morning. Vomiting, no blood. No diarrhœa or melæna.

On examination. Marked pallor. No finger clubbing, no petechiæ. Pulse rate, 110. Apex beat two inches outside nipple line; forcible. Blowing aortic diastolic murmur. Diffuse abdominal tenderness and rigidity.

Urine. A small amount of albumen; a moderate number of squamous cells, fair number of red cells, an occasional leucocyte, and a small number of cocci. 
Clinical Diagnosis. Subacute bacterial endocarditis; mesenteric embolism.

On 14/12/1942 at 10 p.m. he was comfortable and had improved since admission. At 11.15 p.m. he collapsed. When seen, comatose with stertorous breathing and profuse sweating. His blood count showed 35 per cent hæmoglobin with a well-marked polymorphonuclear leucocytosis (polymorphs, 82 per cent; total leucocytes, 43,600 ).

He died at 1.20 a.m. the following morning.

Post-mortem report. (Dr. C. V. Harrison.)

Subacute infective endocarditis. Old rheumatic endocarditis. Mycotic aneurysm of mesenteric artery. Hæmoperitoneum. Very pale. Rigor mortis present. Abdomen rather full. No other lesion.

Abdominal cavity: Distended with enormous quantities of fresh blood.

Heart: Right side normal. Mitral valve thickening but no shortening. No stenosis or apparent incompetence. Slight thickening of posterior auricular wall. Left ventricle hypertrophied and dilated. Aortic valve old rheumatism and infective endocarditis, the latter on the aortic aspect of the aortic cusp of the mitral and the adjacent cusp of the aortic. It took the form of an ovoid, almost "puff ball " thrombus attached to the aortic valve with granular vegetations adjacent to it.

Blood vessels: There was an embolus in one of the main branches of the mesenteric artery. This had caused a mycotic aneurysm in the mesentery corresponding to the last two feet of small intestine. This had burst on its posterior aspect with a massive hæmorrhage.

Small intestines: Normal in spite of the aneurysm of the mesenteric artery. Stomach, colon, and appendix : normal.

Spleen : Shows a reaction in the form of a pale cellular pulp with not much softening.

Kidneys: Right kidney showed one healing infarct and a few minute petechiæ. Left kidney showed a few petechiæ. Ureters, bladder, and prostate, normal.

\section{SUMMARY}

Three new cases of bacterial aneurysm are described, one of the femoral artery, one probably of the radial artery, and one of the mesenteric artery. The last ruptured, causing death from hæmorrhage into the peritoneal sac. The post-mortem findings are recorded in two cases.

Another nineteen cases have been collected, cases reported since 1923 when the subject was fully dealt with by Stengel and Wolferth. These have been analysed.

I am indebted to Dr. J. P. Steel for access to Case 1 and to the case sheets of Smithdown Road Hospital in search for further aneurysms. Professor Henry Cohen also allowed me to scrutinize his notes of recent cases of bacterial endocarditis. Dr. Capon kindly supplied the notes for Case 2 and Dr. G. Sanderson those for Case 3. Dr. C. V. Harrison performed the post-mortem examinations on Cases 1 and 3.

\section{REFERENCES}

Areta, T. (1935). Sem méd. B. Aires, 42, 645.

Aschner, P. W. (1932). Libman Anniversary Volumes, 1, p. 75.

Bain, C. W. C., and Wray, S. (1941). Brit. med. J., 132.

Crane, A. R. (1937). Arch. Pathol., 24, 634.

Eppinger, H. (1887). Arch. klin. Chir., 35, Suppl. Hft. 1.

Gage, Mims (1934). Amer. J. Surg., 24, 667.

Garland, H. G. (1932). J. Path. Bact., 35, 334.

Goodhart, J. (1877). Trans. Path. Soc. Lond., 28, 107.

Knighton, J. E. (1937-8). New Orleans med. J., 90, 646.

Koch, V. M., and Nuzum, T. A. (1940). Arch. intern. Med., 14, 522

Lippincott, S. W. (1940). Canad. med. Ass. J., 43, 115.

Nicholson, G. H. B. (1940). Amer. Heart J., 20, 357.

Ponfick (1873). Virchows Arch., 58, 528.

Stengel, A., and Wolferth, C. C. (1923). Arch. intern. Med., 31, 526.

Taylor, W. N., and Reinhart, H. L. (1939). J. Urol., 42, 21. 